\title{
Expectations of nursing students prior to a skills-based exam performed in clinical practice
}

\author{
Mariette Bengtsson ${ }^{* 1}$, Birgitta Dahlquist ${ }^{2}$, Elisabeth Carlson ${ }^{1}$ \\ ${ }^{1}$ Faculty of Health and Society, Department of Care Science, Malmö University, Sweden \\ ${ }^{2}$ Department of Clinical Sciences, Division of Orthopaedics, Skane University Hospital, Sweden
}

Received: November 23, 2015

Accepted: February 21, 2016

Online Published: March 22, 2016

DOI: $10.5430 /$ jnep.v6n8p22

URL: http://dx.doi.org/10.5430/jnep.v6n8p22

\begin{abstract}
Students perform bedside exams in different real life settings and their performance are assessed. They are prior to and during the exam nervous, and for that reason make avoidable mistakes. The aim was to explore undergraduate nursing students' feelings, reasoning, and preparations prior to a skill-based exam performed in clinical practice. Data was collected by interviews performed as unstructured everyday dialogues based on two main questions: "Tell me how you feel when you think of the coming skill-based exam, and how are you reasoning and prepare for this exam". Eigtheen Swedish nursing students (17 women and 1 man, median age of 28, range 22-43 years) in their final semester of a three-year nursing programme were interviewed. The collected data were analysed by content analysis, and the findings were interpreted into one theme, Balancing fear with competence, which is a metaphor for students' turbulent emotions and thoughts prior to a real life skill-based exam. The subthemes Being in an emotional turmoil, Attaining increased knowledge and skills and Preparing for collaboration comprise the different experiences. The students were fearful of failing and were focused on the assessment itself, which created nervousness, and stress. They expressed a lack of self-confidence, and were not sure of their capability after three years of nursing studies. By supporting the students to develop their awareness of their own theoretical knowledge as well as their emotional, practical, and interpersonal skills by using different teaching methods, the students might handle the stressful nature of a bedside exam better.
\end{abstract}

Key Words: Assessment, Knowledge, Nursing education, Practical examination, Skills

\section{BACKGROUND}

The demands and expectations from patients and their relatives, as well as from other health care professionals of registered nurses' competence are high in many countries. To meet these challenges and ensure patient safety while maintaining high quality care registered nurses need to be able to work independently as well as interprofessionally, thereby incorporating qualities that include evidence-based theoretical knowledge, and practical skills. ${ }^{[1]}$ Therefore, to ensure that newly graduated nurses are fit for practice it is vital that theoretical knowledge and practical skills are assessed near graduation. Nursing students are expected, in time for graduation, to have gained satisfactory knowledge and skills in line with professional standards and requirements and the ability to communicate with other health care professionals and patients with respect, empathy and responsiveness. ${ }^{[2-5]}$ Therefore, nursing students' progress towards attaining the full role of a nurse must be facilitated throughout the whole study programme, and the students' knowledge and practical skills should be evaluated and assessed summatively and formatively in relation to the learning outcomes pronounced in the syllabuses. ${ }^{[6]}$ Students should be able to demonstrate

${ }^{*}$ Correspondence: Mariette Bengtsson; Email: mariette.bengtsson@mah.se; Address: Faculty of Health and Society, Institution of Care Science, Malmö University, SE 20506 Malmö, Sweden. 
how to perform and act in different real-life situations; therefore, skill-based practical exams are needed..$^{[2,3,7]}$ Miller's Pyramid of Assessment ${ }^{[8]}$ provides a framework for assessing clinical competence regardless of context (see Figure 1). This model starts with the assessment of cognition and ends with the assessment of behaviour in practice. The lowest level of the pyramid is the recall of factual knowledge (knows) which can be assessed by written exams, followed by application of knowledge (knows how). Assessing practical skills can be performed in vitro (shows how) by OSCE (Objective Structured Clinical Examination) or simulations in artificial settings, followed by exams in vivo (does) in a health-care environment were real patients are involved. These exams can be based on observed long and short cases, so called bedside exams. ${ }^{[7]}$ In bedside exams, students take care of a patient and then summarise their findings to one or two examiners who also discuss the student's performance, the patient's need of care, and other relevant topics. ${ }^{[9]} \mathrm{Ra}-$ mani, Leinster ${ }^{[10]}$ and Al-Wardy ${ }^{[9]}$ point out that assessing performance in real life settings during daily patient care is the only exam reaching the highest level of the pyramid. However, Wass et al. ${ }^{[11]}$ have described this form of exam as a real challenge for educators. It is difficult to ensure the validity and reliability due to the use of multiple examiners across different cases. The involved patients' conditions and care situations vary, so it is problematic to create some standardization. Therefore, it is important to use and assess students based on a well-defined protocol. ${ }^{[8]}$

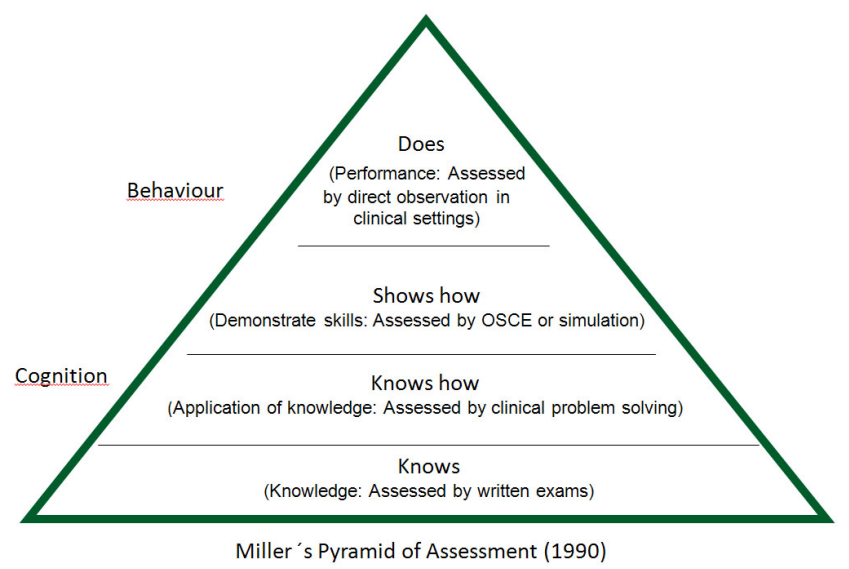

Figure 1. Millers's Pyramid of Assessment modified by Ramani S, Leinster S, AMEE Guide no 34: Teaching in the clinical environment. Medical Teacher, 2008:30(4):347-364

As previously discussed by Clarke $e t$ al. ${ }^{[12]}$ students usually consider exams to be stressful events fearing the outcomes since their future depends on the results of the examinations. In particular, bedside tests seem to induce stress and nervous- ness among nursing students. ${ }^{[13-15]}$ According to national Swedish figures, approximately 5 percent of the students fail at the first opportunity to perform the practical bedside exam included in the Swedish National Clinical Final Examination. Among these students, 10 percent need to perform two re-exams or more before they pass, and students make mistakes because of their nervousness. Further, Tiwari et al. ${ }^{[16]}$ discussed that stress induced by clinical assessment could inhibit a holistic clinical learning experience, and concluded that nurse educators need to implement assessment practice that support student learning in a positive way. Thereby, it is important for nurse educators to understand how students reasoning and prepare for skill-based clinical exams in order to provide teaching strategies that will support student preparation, and to prevent students' nervousness. There is an abundance of literature describing stress related to assessments, but little is known about how students prepare and prevent stress due to bedside exams from their own perspective. The aim of this study was to explore undergraduate nursing students' feelings, reasoning, and preparations prior to a real life skill-based exam performed in clinical practice just before graduation.

\section{RESEARCH DESIGN}

The study used a qualitative descriptive, design, based on interviews with nursing students in their final semester, preparing for a forthcoming practical skill-based exam included in the Swedish National Clinical Final Examination for the Bachelor of Nursing degree.

\subsection{Participants}

All included students started their third and final year in 2009 ( $\mathrm{N}=174$ ), 81 in January (group A) and 93 in August (group B). In total 18 students volunteered, 9 from each group of students. Among these were 17 women and 1 man, with the median age of 28 (range 22-43) years. Half of the students graduated in June 2009, and the other half in January 2010.

\subsection{Setting}

To assess third-year nursing students' clinical competence and ensure that they have gained knowledge and skills as required by health care authorities, the Swedish National Clinical Final Examination started as a project in 2003. ${ }^{[2]}$ The national exam summarises the three-year undergraduate programme and consists of a theoretical written exam, a drug calculation test, and a practical skill-based exam. The objective of the examination is to meet and reflect the requirements of the Higher Education Ordinance, as well as the expectations of the professional health care field, of what a nurse at undergraduate level is qualified to do. The practical exam takes place in a real-life setting, in a hospital or 
in municipal care, where students attend their final clinical placement. Each student act as a nurse and take care of a patient in need of comprehensive medical and nursing care for three hours. The student is observed by an experienced registered nurse who evaluates the student's performance based on a protocol. At the end of the exam, the student, the observing nurse, and the clinical teacher, from the affiliated university and ultimately responsible for the exam, discuss the student's performance. The medical and nursing care the student has performed is reflected on and finally graded failed or passed.

\subsection{Data collection}

The students in current study were interviewed between seven to ten weeks before the practical skill-based bedside exam. The interviews were performed as an unstructured everyday dialogue between the second author (BD) and the students, based on two overarching questions: "Tell me how you feel when you think of the coming skill-based exam" and "Tell me how you reasoning and prepare for this exam". The two questions were broad and open ended, and the students had opportunity to express their perspectives. The interviews were guided almost entirely by the students just as Parahoo ${ }^{[17]}$ recommend, and the students were encouraged to give examples based on their own experience. As suggested by Patton, ${ }^{[18]}$ the interviewer also encouraged the students to narrate thoughts, and deliberately excluded concepts and words related to "assessment". The purpose of the interviews was to understand participants' experiences through their own words and perspectives so new areas could be explored. However, supplementary questions were asked when the dialogue stopped and needed to move forward. The discussions in the current study were lively, and the students seemed to be comfortable and open when sharing their thoughts. All interviews were performed near the ward where the students carried out their clinical training. The interviews took 14 to 48 minutes each (median 30 minutes), and were audio recorded and transcribed verbatim by the second author (BD). The interviewer documented the key points discussed, and immediately afterwards summarised the discussion in the presence of the student.

\subsection{Analysis}

The transcriptions of the interviews, marked 1 to 18 (1-8 group A, 9-18 group B), were analysed using qualitative content analysis inspired by Downe-Wamboldt. ${ }^{[19]}$ The purpose was to explore the content and the meaning of the narratives, to determine patterns, and to link these together in a realistic system of categories in order to extract their meaning. This qualitative analysis was combined with quantification based on the number of students and not the number of cat- egories. ${ }^{[20]}$ To get immersed in the data the text was read through before meaning units were coded. This procedure was performed several times, and to maintain the reliability and the stability of the codes this process started at different pages each time. After the meaning units were identified, the authors $(\mathrm{BD}, \mathrm{MB})$ checked if all aspects of the content were covered in relation to the aim by comparing the final list of meaning units with the original text. No important information was left out, so the analysis could continue by condensing extended meaning units. Similar codes were then grouped together, and during this categorisation process, sub-headings, categories, and sub-themes were identified.

\subsection{Rigour}

Two of the researchers (BD, MB) performed the different steps of the analysis separately, to increase its validity. During the analysis process, the emerging results as well as the interpretations have been checked and discussed among all three authors until consensus was reached. Credibility was ensured by presenting data by verbatim quotes from the students, verifying the authors' interpretation. ${ }^{[18]}$ The quotations are marked S1 to S18 illustrating the participants' experiences associated with each category. The authors of this study were familiar with the context and the examination, but assessed none of the students included in the study. In addition, to confirm the dependability, to verify the results, and to estimate the saturation of the collected data, 347 students from 15 Universities in Sweden who performed the same exam in January 2015 answered the same questions in a survey. The findings in our study were confirmed and this strengthen the validity and transferability of our result. This action could be considered as a form of respondent validation.

\subsection{Ethical aspects}

The study was performed in accordance with the ethical principles based on the World Medical Association Declaration of Helsinki, ${ }^{[21]}$ and approved by the Director of the Nursing Programme and the Ethics Committee at Malmö University (Dnr HS60-09/139:10). The participating students were informed orally and in writing about the study, and gave their written, informed consent prior to the study. All students were informed about their right to withdraw at any time without consequences for their studies, and were guaranteed confidentiality.

\section{Findings}

The main message that the students communicated was interpreted as the overarching theme Balancing fear with competence, based on the three subthemes Being in an emotional turmoil, Attaining increased knowledge and skills and Prepar- 
ing for collaboration. The students feared the assessment itself, and to be assessed led to anxiety, nervousness, and stress. Even though, the exam should take place in a wellknown clinical setting, the students reported the same level of stress as they had experienced prior to any of their theoretical exams. However, one student mentioned that feeling stressed had previously helped her to perform better, and she hoped this would happen this time as well. The students indicated that the practical exam had been in their focus throughout the whole semester. They talked about gaining some "basic knowledge", but what this "basic knowledge" included was difficult for them to explain. During the exam, the students will be encouraged to reflect aloud. Some students had done this during their clinical practice and were used to that. For other students, this should be a new experience, and they did not feel comfortable with that. The students thought the exam is a form of quality control of the level of knowledge of newly graduated nurse, and most of the students mentioned the word "confirmation". They described how they hope for observing nurses to acknowledge and confirm them as ready to function as nurses. The students expressed a luck of selfconfidence, and they were not sure of their capability. Some students thought that by performing the exam, they will be able to demonstrate for themselves as well for others that they can work as a nurse and are ready for practice. The students also wanted feedback on their performance. "I expect the person who assess me to tell me what I can do better and what I need to think about, even though I pass" (S16, group B). Identified sub-headings, categories, and sub-themes are presented in Table 1. Quotations are woven into the text below with the sub-themes used as headings.

Table 1. An overview of sub-headings, categories and sub-themes leading to the main theme Balancing fear with competence

\begin{tabular}{lll}
\hline Sub-headings & Categories & Sub-themes \\
\hline $\begin{array}{l}\text { Judgement } \\
\text { Failure }\end{array}$ & Fear of the assessment & $\begin{array}{l}\text { Being in an } \\
\text { emotional turmoil }\end{array}$ \\
$\begin{array}{l}\text { Unprepared situation } \\
\text { Complex patient cases }\end{array}$ & Fear of the conditions & \\
$\begin{array}{l}\text { Unclear circumstances } \\
\text { Theoretical understanding } \\
\text { Practical ability } \\
\text { Capacity for empathy }\end{array}$ & Gaining competences & Attaining increased \\
Logical thinking & & \\
Holistic perspective & & \\
Obligation & Strategic preparation skills \\
Care team & & \\
Collaboration & & Preparing for \\
Partnership & & collaboration \\
Own power of action & Personal resources & \\
Leadership & & \\
\hline
\end{tabular}

Published by Sciedu Press

\subsection{Being in an emotional turmoil}

The students feared the practical exam and expressed their hesitation in regard to the assessment and in particular the feeling of "being judged". The students expressed that this exam was far more important than the other exams already taken, as this was a practical bedside exam and their final exam. The students felt strongly that they did not want to fail as this exam particular confirmed if they had sufficient qualifications or not. They expressed that they had no insight of their own capability, and they were therefore not sure of passing.

"To have someone who assess me, and listens to what I say, and sees all the wrong things I do, and then judge me if I am good enough, that is terrifying. I do not know if I have enough skills to pass" (S18, group B).

To make mistakes and jeopardize the patient's safety, and therefore fail, were the students' main concerns. They knew that they will have the possibility to discuss minor mistakes afterwards, and thereby pass the exam.

"It is reassuring to know that I have a chance to correct a minor mistake unless I have exposed the patient to any risks" (S12, group B).

The students said that they thought it might be disconcerting to be observed, "to be shadowed", during the exam. The students also feared that their previous preceptors' and the observing nurses' perceptions of nursing care would differ in some aspects. Some of the students had heard from students from the previous years that the observing nurses had different ways of interpreting their duties as an observer.

"Those three hours can be demanding and stressful depending which patient I will get. It also depends who the observing nurse is, and if the nurse has some negative feelings for me." (S6, group A).

The students also feared the conditions since they did not know in detail what was going to happen. They must face a new situation, deal with new dilemmas, and perhaps care for a patient with an unfamiliar diagnosis. The students feared the circumstances to be difficult since the assessment was to be based on one unknown single situation.

"What happens if the patient is severely ill and I cannot manage? This makes me unsure, because I cannot plan my actions in advance." (S1, group B). 
One student was terrified since she knew that she must go to a different ward from her previous clinical placement to perform the exam.

"I have not visited the ward yet where I am going to perform my exam, and it terrifies me to know that I have to go to a ward where I have not been practicing before, what happens if I cannot find the things I need?” (S4, group A).

Another student was pleased with the same situation and saw it as an advantage, and felt that she would therefore be assessed more objectively.

\subsection{Attaining increased knowledge and skills}

The students gained competences to balance the fear caused by the assessment of the exam. It appears that all except one of the students felt the need to acquire more knowledge and skills before the exam. The students mentioned theoretical knowledge in most of the interviews, and talked about a willingness to update their knowledge by reading general guidelines, regulations, and scientific literature.

"I've been thinking about what to revise, yes, general regulations, and just look through the medical technology guidelines to ensure that, hopefully, I won't make mistakes." (S17, group B).

On the contrary, the student who did not feel the need to attain more knowledge prior to the exam expressed her thinking as the following quote illustrates: "I think I already have acquired sufficient knowledge, and have no plans to further update myself." (S1, group A).

The students expressed that they felt prepared after having had the opportunity to meet patients with different diagnoses during clinical practice, but they were still unsure of their ability to pass the exam. During their clinical practice they asked for feedback on their performance.

"I am doing my clinical practice right now, and I meet with a lot of patients with different diagnosis, and the final clinical exam now seems more reasonable than it did before. However, I am still not certain of my capability....I want more feedback from my preceptor on my performance..." (S3, group A).

Five of the students planned to practice the exam procedure during their clinical supervision, in purpose to be better prepared. For some students the theoretical knowledge was in focus, and for others their practical skills were a priority. The students considered that it was their own responsibility to ensure that they acquired adequate understanding, and they studied by their own, even though one student said: "You have to set a limit and decide that enough is enough with the reading and preparation. However, the number of hours per week that we students can use for our own readings are limited." (S15, group B).

The students tried to prepare themselves by strategically plan how they could carry out the examination. Nearly all of the students talked about the importance of thinking logically, and intended to solve the problems progressively as they arose.

"I'm going to focus on what I believe will arise, but if something else happens, I have to change course quite quickly.... Will I be able to that?'(S2, group A).

They all agreed that it was important to have a holistic perspective, and it was their responsibility to reflect critically on outcomes, so that their patients would receive good care.

"If a patient's blood pressure falls, I will not administrate antihypertensive medication even if it is prescribed." (S9, group A).

\subsection{Preparing for collaboration}

Six students remembered that during the introduction in the beginning of the semester the students had been informed that they could ask questions, and ask for help from the team if it is required. The students also knew they could use other external resources, but they were unsure if they would dare asking for help, or receive help and support if they asked.

"I know that I am not alone, but can receive help when I needed it? It is stressful not to know" (S5, group A).

The students were aware of the importance to demonstrate their ability to collaborate with other health-care professionals in order to pass the exam. However, this collaboration could entail risks, since the students did not know if they would be supported or not.

"The staff can run around me, but I know what I have to do... I will focus and cooperate with my team no matter what" (S8, group A).

The students revealed that it was up to them to be in charge and have the care of the patient in focus during the exam. This insight created not only feelings of empowerment, but also concerns. The students considered themselves as the main resource, but they were not sure if they were capable 
enough to cope with the situation. After the exam the students hoped to be more aware of their own abilities, strengths, and weaknesses. However, three students felt that the insecurity triggered them to be more rational, active and focused during the exam.

"I say to myself: Why make this exam more complicated than needed? If something unfamiliar comes up I will solve it in the same way I usually solve problems and I will act as if it is an ordinary day at work.” (S7, group A).

One of the skills that will be assessed during the exam is the ability to delegate, and to act as the leader of the team caring for the patient. The students knew that they have to take the lead and the command of the care given. However, they were uncertain if they would be able to handle that.

"I am also the leader of the team, and I have the mandate to delegate if it is necessary, and I hope I will managing that" (S18, group B).

\section{Discussion}

Assessment of clinical competence should provide insight into students' actual performance, as well as the students' capacity to adapt new knowledge in a lifelong perspective. However, this study illustrates that the participating nursing students were more focused on the assessment itself, than on the aim of the practical exam, i.e. to demonstrate the skills needed to cope with the nursing role. The students were nervous and had the forthcoming exam in focus during the whole semester. The exam was planned to be performed as an "ordinary day at work", in line with the top level of Miller's pyramid where students are assessed by direct observations in clinical settings. ${ }^{[8]}$ Nevertheless, the students perceived nervousness even though they should be familiar with the context after several weeks of practical training. The students' perceived stress should be regarded as a negative occurrence, even though some of the students needed this stress to peak their performance. For students, the key point in handling stress is to be in control of a situation. Nechita and associates ${ }^{[22]}$ argues that the human being experience stress when there is a discrepancy between the demands made and the resources available. Students cope differently with stress, and in our study, it appeared that one coping strategy while preparing for the exam was to increase the level of theoretical knowledge by rereading the course literature. A reason for this strategy could be that the nursing students experienced that they had not time to read all course literature that they wanted during earlier semesters, and therefore needed to catch up prior to the exam. ${ }^{[23]}$ Another strategy was to intensify training of practical skills, and to use internal resources

Published by Sciedu Press by stepping up their performance to meet the demands of the examination. In a practical exam were real patients are involved, the students cannot control what is going to happen, but they can learn to control an unknown stressful situation. In general, nursing is considered a challenging, and demanding profession, ${ }^{[24]}$ and nursing graduates need to be prepared for the realities of everyday practice. Therefore assessment of competence, even though it is stressful, is essential for nursing students to ensure that safe care of good quality is given to all patients. ${ }^{[25]}$

In our study the students expressed how important it was for them to pass. They suggested that similar scenarios that are used for the final examination could be practiced under supervision and assessed during clinical practice as preparation, thus reducing the stress. McKeachie \& Svinicki ${ }^{[26]}$ also propose the use of non-graded exams in addition to students' evaluation of each other during their clinical practice. Based on the students' lack of self-confidence we are inclined to agree, and perhaps the real assessment can then be played down, and hence reduce students' stress levels. If students perform the same procedure before the exam and got feedback from other students or preceptors they might to be aware of their capability. The students also requested more feedback from their preceptors during clinical practice. Norcini and Burch ${ }^{[27]}$ argue that constructive feedback during clinical practice has a major influence on learning, and is often more important than the grade attained by examination. They mean that feedback, especially to those students who are anxious, is central for the learning process.

The students in our study were uncertain of their capability after three years of nursing studies, which was a surprise for us. Since the students were near the time for graduation, they ought to have developed some understanding of their strengths and weaknesses. According to Epstein ${ }^{[25]}$ assessments plays an integral role in helping students to identify and respond to their own learning needs. The students in our study had performed other exams related to all four steps presented in Miller's Pyramid of Assessment ${ }^{[8]}$ during their three years of studies in purpose to evaluate their knowledge. Therefore they ought to have some understanding of their capacity. McMullan et al., ${ }^{[28]}$ and Green et al. ${ }^{[29]}$ argue that students can obtain an overview of their own academic achievements and personal growth by using portfolios. However, the students in our study had not used any portfolio or other specific procedures except exams in purpose to highlight their own development during their studies. Critical and reflective tasks and self-assessment which are central to portfolios, could have been of help to gain insight into the students' abilities, and build up their confidence. 
The students planned to use external resources by communicating and interacting with other health care professionals during the bedside exam. However, they were not certain of the outcome of this interprofessional collaboration. Missen et al. ${ }^{[30]}$ have also identified communication and interaction as areas of concern in relation to overall clinical competence of new nursing graduates in their first year of practice. To communicate and interact with colleges and patients, nurses need profession-specific as well as interpersonal skills so that patients will receive safe care of good quality. According to previous studies, ${ }^{[11,32]}$ interprofessional training at clinical education units (CEU), where students from different health care professions work in teams, has the potential to facilitate the development of communication and collaboration skills. Nevertheless, despite that the students in our study, earlier in the nursing program, had practiced communication and collaboration during their clinical practice, and spent two weeks at the CEU prior to the final clinical exam, some students expressed how they felt unsure of their capability for collaboration with other health care professions. One reason for this might be that the stress of being assessed overshadows previously learnt skills.

Examinations and other assessments are important educational tools, but there is no quick-fix strategy to decrease students' stress level for exams. Students need support to change focus from a "being assessed perspective" to "learning for life perspective". Otherwise, from the students' perspective, for example bedside exams which is the highest level of exams ${ }^{[8-11]}$ will only become associated with a system of control instead of one way to attain the proficiency of the nursing role.

\section{Limitations}

In face-to-face interviews, there is always the risk that some informants might feel intimated and afraid of voicing their opinion. In this study the students knew that they were not to be assessed by the interviewer, and could therefore openly discuss their feelings and thoughts which strengthens the result. Collected data is based on 18 students' perspectives, but students world-wide perceive some level of stress prior exams. However, the findings in current study may not be transferrable to all settings due to cultural diversity.

\section{Conclusions}

In nursing education, it is essential to assess nursing competencies for the future professional role, such as the assessment of clinical competence by bedside exams. Unfortunately, the students in current study were nervous and fearful of failing. They were focused on the assessment itself and insecure of their own capability to perform the forthcoming clinical practical exam in a correct manner. However, they tried to balance their nervousness, and stress prior the exam by increasing their competence and thinking strategic. For an educator, this information is important, to be able to create relevant learning activities helping the students to succeed and pass the exam. Por ${ }^{[33]}$ suggests that supporting students to develop their awareness of their own theoretical knowledge as well as their emotional, practical, and interpersonal skills by using different teaching methods, the students might gain control of their main concerns related to exams. Based on the results in current study we recommend that teachers, mentors and preceptors should support nursing students to develop their ability to reason critically, and collaborate with other professionals during the entire nursing program. The students should learn how to solve problems, and be instructed to be open to new approaches in different contexts in order to attain a better professional understanding. Clinical teachers and preceptors should encourage students to dare to attempt new things, and build up their confidence by given feedback. Thereby, hopefully students might gain control of their main concerns and find real life skill-based exam less stressful.

\section{ACKNOWLEDGEMENTS}

The authors extend their gratitude to all students participating in the study for sharing their thoughts on being assessed in clinical practice.

\section{Conflicts of InTERest Disclosure}

The authors declare that there is no conflict of interest.

\section{REFERENCES}

[1] Cronenwett L, Sherwood G, Barnsteiner J, et al. Quality and safety education for nurses. Nursing Outlook. 2007; 55(3): 122-131. PMid: 17524799.http://dx.doi.org/10.1016/j.outlook. 2 007.02 .00

[2] Athlin E, Larsson M, Söderhamn O. A model for a national clinical final examination in the Swedish bachelor programme in nursing. Journal of Nursing Management. 2012; 20(1): 90-101. PMid: 22229905. http://dx.doi.org/10.1111/j.1365-2834.2011.01278.x

[3] Ziegert K, Ahlner Elmqvist M, Johansson UB, et al. How the final Swedish clinical exam prepares the nursing students for their future challenges qualitative analysis. Creative Education. 2014; 5(21): 1887-1894. http://dx.doi.org/10.4236/ce.2014.521211

[4] Spector N, Alexander M. Exit exams from a regulatory perspective. Journal of Nursing Education. 2006; 45(8): 291-292. PMid: 16915984. 
[5] Bradshaw A, Merriman C. Nursing competence 10 years on: fit for practice and purpose yet? Journal of Clinical Nursing. 2008; 17(10): 1263-1269. PMid: 18416778. http://dx.doi.org/10.1111/j $.1365-2702.2007 .02243 . x$

[6] Light G, Cox R, Calkins S. Learning and Teaching in Higher Education: The Reflective Professional 2nd ed. Thousand Oaks, California: Sage publications Inc, 2009.

[7] Mårtensson G, Löfmark A. Implementation and student evaluation of clinical final examination in nursing education Nurse Education Today. 2013; 33(12): 1563-1568. PMid: 23398913. http: $/ /$ dx.doi.org/10.1016/j.nedt.2013.01.003

[8] Miller G. The assessment of clinical skills/competence/performance. Academic Medicine. 1990; 65(Suppl 9): 63-67. PMid: 2400509. http://dx.doi.org/10.1097/00001888-199009000-00045

[9] Al-Wardy N. Assessment of methods in undergraduate medical education. Sultan Qaboos University Medical Journal. 2010; 10(2): 203-209. PMid:21509230.

[10] Ramani S, Leinster S. AMEE Guide no. 34: teaching in the clinical environment. Medical Teacher. 2008; 30(4): 347-364. PMid: 18569655. http://dx.doi.org/10.1080/01421590802 061613

[11] Wass V, Van der Vleuten C, Shatzer J, et al. Assessment of clinical competence. Lancet. 2001; 357(9260): 945-949. PMid: 11289364.

[12] Clarke S, McDonald S, Rainey D. Assessing registered nurses' clinical skills in orthopaedics. Nursing Standard. 2012; 26 (43): 35-42. PMid: 22860344. http://dx.doi.org/10.7748/ns2012.06.2 6.43.35.c9174

[13] Levett-Jones T, Gresbach J, Arthur C, et al. Implementing a clinical competency assessment model that promotes critical reflection and ensures nursing graduates' readiness for professional practice. Nurse Education in Practice. 2011; 11 (1): 64-69. http: //dx.doi.org/10.1016/j.nepr.2010.07.004

[14] Lilja Andersson P, Ahlner-Elmqvist M, Johansson UB, et al. Nursing students' experiences of assessment by the Swedish National Clinical Final Examination. Nurse Education Today. 2013; 33(5): 536-540. http://dx.doi.org/10.1016/j.nedt.2011.12.004

[15] Blomberg K, Bisholt B, Engström Kullén A, et al. Swedish nursing students' experience of stress during clinical practice in relation to clinical setting characteristics and the organisation of the clinical education. Journal of Clinical Nursing. 2014 Aug; 23(15-16): 2264-71. PMid: 24393384. http://dx.doi.org/10.1111/jocn. 12506

[16] Tiwari A, Lam D, Yuen KH, et al. Student learning in clinical nursing education: Perceptions of the relationship between assessment and learning. Nurse Education Today. 2005; 25(4): 299-308. PMid: 15896415.

[17] Parahoo K. Nursing Research: Principles, Processes and Issues. Second edition. New York: Palgrave Macmillan; 2006.

[18] Patton MQ. Qualitative, research \& evaluation methods. Thousand Oaks, California; Sage publications Inc; 2002.

[19] Downe-Wambolt B. Content analysis: method, applications and issues. Health Care for Women International. 1992; 13(3): 313-321.
PMid: 1399871. http://dx.doi.org/10.1080/07399339209 516006

[20] Berg BL. Qualitative research methods for the social sciences. Boston: Allyn and Bacon; 2001.

[21] WWA, 2008 World Medical Association Declaration of Helsinki (current version 2014-12-20). http://www . wma. net/en/30publica tions/10policies/b3/index.html

[22] Nechita F, Nechita D, Pîrlog MC, et al. Stress in medical students. Romanian Journal of Morphology \& Embryology. 2014; 55(3 Suppl): 1263-1266. PMid: 25607418.

[23] Bengtsson M, Ohlsson B. The nursing and medical students' motivation to attain knowledge. Nurse Education Today. 2009; 30(2): 150-156. PMid: 19692152. http://dx.doi.org/10.1016/j.n edt. 2009.07.005

[24] Jones MC, Johnston DW. A critical review of the relationship between perceptions of the work environment, coping and mental health in trained nurses, and patient outcomes. Clinical Effectiveness in Nursing. 2000; 4(2): 75-85. http://dx.doi.org/10.1054/cein. 20 00.0109

[25] Epstein RM. Assessment in Medical Education. N Engl J Med. 2007; 356: 387-96. PMid:17251535. http://dx.doi.org/10.1056/N EJMra054784

[26] McKeachie WJ, Svinicki M. McKeachie's teaching tips. Boston: Houghton Mifflin company; 2006.

[27] Norcini J, Burch V. Workplace-based assessment as an educational tool: AMEE Guide No.31. Medical Teacher. 2007; 29(9): 855-871. PMid: 18158655.

[28] McMullan M, Endacott R, Gray MA, et al. Portfolios and assessment of competence: a review of the literature. Journal of Advanced Nursing. 2003; 41(3): 283-294. PMid: 12581116.

[29] Green J, Wyllie A, Jackson D. Electronic portfolios in nursing education: a review of the literature. Nurse Educ Pract. 2014 Jan; 14(1): 4-8. PMid: 24090523. http://dx.doi.org/10.1016/j.n epr.2013.08.011

[30] Missen K, McKenna L, Beauchamp A. Registered nurses' perceptions of new nursing graduates' clinical competence: A systematic integrative review. Nurs Health Sci. 2015 Nov 23. [Epub ahead of print] PMid: 26592371. http://dx.doi.org/10.1111/nhs. 12249

[31] Freeth D, Reeves S, Goreham C, et al. Real life' clinical learning on an interprofessional training ward. Nurse Education Today. 2001; 21(5): 366-72. PMid: 11403583.

[32] Carlson E, Pilhammar E, Wann-Hansson C. The team builder: The role of nurses facilitating interprofessional student teams at a Swedish clinical training ward. Nurse Education in Practice. 2011; 11 (5): 309-313. PMid: 21342789. http://dx.doi.org/10.1016/j.n epr.2011.02.002

[33] Por J. A pilot data collecting exercise on stress and nursing students. British Journal of Nursing. 2005; 14(22): 1180-1184. PMid: 16509434. http://dx.doi.org/10.12968/bjon.2005.14.22. 20169 